\title{
Enterolith lleus As A Complication Of Small Bowel Diverticulosis
}

\author{
Maj D Bowley \\ FRCS(Eng),RAMC \\ Senior House Officer \\ Lt Col CAJP Royle
FRCS(Eng),RAMC
Consultant
}

Department of General Surgery, MDHU Frimley Park Hospital, Portsmouth Road, Frimley, Surrey GU16 $5 U J$.

SUMMARY: We report a case of small bowel obstruction which was found to be due to an enterolith obstructing the distal ileum in the manner of "gallstone ileus." The enterolith had formed in an acquired jejunal diverticulum. We review the accepted mechanism of formation of these "stones" and propose a protocol for treatment of this rare $\bar{乛}$ complication.

\section{Introduction}

Small bowel diverticula are uncommon. In a postmortem series of 218 consecutive examinations duodenal diverticula were found in $2.8 \%$ and jejunal or ileal diverticula in $4.6 \%$ of cases (1). They are usually asymptomatic but may cause malabsorption, haemorrhage, diverticulitis or perforation. The rarest complication is obstruction due to an enterolith forming within a jejunal diverticulum (2).

\section{Case history}

A sixty-eight year old man presented with abdominal pain and vomiting of forty-eight hours duration. His abdomen was distended, tender and high-pitched bowel sounds were heard. He had no medical history of note.

$\mathrm{X}$-rays were consistent with a clinical diagnosis of small bowel obstruction and after a period of fluid resuscitation and a naso-gastric suction, he was taken to theatre.

At laparotomy a single, large enterolith was found obstructing the distal ileum and multiple jejunal diverticula were noted, some containing other enteroliths. No other abnormalities were discovered.

As the diverticula were confined to a short segment and contained multiple enteroliths the segment was excised and a single layer anastomosis was performed.

The patient recovered and is well after nine months of follow-up.

\section{Discussion}

Jejunal diverticula may be congenital or acquired. Congenital diverticula appear on the anti-mesenteric border of the bowel (3). They contain all three layers of the intestinal wall rather than adult jejunal diverticula which are composed of mucosa and submucosa protruding through the muscle coat and appear on the mesenteric 0 border of the bowel. The adult-type are thought to be pulsion diverticula arising due to intestinal dyskinesis (2).

Enteroliths arise in diverticula as abnormal bowe motility and stasis promote bacterial overgrowth. Tha leads to bile salt deconjugation and precipitation, wi foreign bodies such as undigested food particles providirf $\mathbb{\Phi}$ a nidus (4).

If possible, the enterolith should be broken up manualfy and milked into the colon. If this cannot be achieved, the enterolith should be removed via a proximal enterotomy (

Bowel resection is recommended in the presence of inflammation, necrosis, perforation or if multiple diverticula with enteroliths are present (6).

\section{REFERENCES}

1. NOER T. Non Meckelian diverticula of the small bowel. Acta Chir Scand 1960; 120: 175-9.

2. Beal SL, Walton CB, BodaI BI. Enterolith ileus? resulting from small bowel diverticulosis. Am $J$ Gastroenterol 1987; 82(2): 162-4.

3. KuzAat M, CARneIro PMR, SPITZ L. Jejunal diverticulum in a child with small bowel obstruction. $J \widetilde{\Phi}$ $R$ Coll Surg Edinb 1992; 37: 195.

4. Kurz R, Buck J. Heinkelein J. Ileus of the small bowel caused by an enterolith. $Z$ Gastroenterol 1994; 32(9): 497-9.

5. KING PM, BIRD DR, EREMIN O. Enterolith obstruction of the small bowel. $J R$ Coll Surg Edinb 1958; 30(4): 269-70.

6. LOPEZ PV, WELCH JP. Enterolith intestinal obstruction $\frac{7}{O}$ owing to acquired and congenital diverticulosis. Dis Colon Rectum 1991; 34(10): 941-4. 